\title{
Mechanics Analysis of 110kV Suspension-Type Composite Insulators in Ice Coating and Wind Loads Conditions
}

\author{
ZHAO Xin-ze *, Fu Zhi-cheng , Zhao Mei-yun, Wang Lei, Wu Yang \\ Collaborative Innovation Center for Energy Equipment of Three Gorges Region, China Three Gorges University, Yichang 443002
}

\begin{abstract}
Composite insulators are insulation parts which are used to withstand power load and all kinds of stress applied by wires in transmission lines, the stress offen cause fracture and brittle fracture of core rods in the operation.In this paper,composite insulators, running in the ice coating and wind load conditions of Three Gorgee Area,is chose as the research object.Based on theory of mechanics of materials end experiment results carried out in existing papers and simulation of the bending stress of composite insulators, the stress failure of the insulator (FXBW4-110/70) in $110 \mathrm{kV}$ transmission lines were studied.The results show that, under the single action of tension,torsion and bending load,the instantaneous fracture of $110 \mathrm{kV}$ suspension-type composite insulators could not happen in the Three Gorgee Area . The line galloping and sleet jump of conductor make the fracture of bent insulators happen in the locations near towers. The results also found that the longrunning composite insulators could make stress concentration position shift, eventually lead to brittle fracture.
\end{abstract}

\section{Introduction}

Composite insulator is the insulation parts of transmission lines, not only withstood the power load, but also suffered various stress by wire clamp. It has excellent antifouling performance, which is now widely used throughout the country. The running composite insulators in China have more than 6 million cigarettes (converted into $110 \mathrm{kV}$ ), which is the largest use of composite insulator in the world.

According to analysis composite insulator running accident statistic in 2000 by CIGRE, the mechanical faults of composite insulator are mainly for mandrel fracture and brittle fracture. The brittle fracture of composite insulator core rod is often studied. The results show that the brittle fracture of core rod is caused by stress corrosion effect for a long time [1].But few people study the non stress corrosion of mandrel. It is reported that a double bar hanging composite insulator, which is located in a road of overhead transmission line of Yunnan Power grid corporation, happened rupture run in the netting after three months on January 28, 2012 .Literature [2] through studying to detect the fault insulator, it is concluded that composite insulator in the case of the stress corrosion, external conditions such as ice jumping away from the tower of low voltage side suffers larger bending stress, leading to the insulator rupture. So the study of mechanical properties of core rod under extreme operating conditions is of great significance to prevent fracture of rods.

In this paper, the composite insulator of the Three Gorges Area under the ice wind load conditions (ice 35 $\mathrm{cm}$, wind speed of $25 \mathrm{~m} / \mathrm{s}$ ) is studied as a research object, by using the theory of mechanics of materials and the existing experimental results to analysis and calculate the force. Then through the finite element simulation to analysis the bending stress of the FXBW4-110/70 composite insulator, which is commonly used for $110 \mathrm{kV}$ transmission lines.

\section{Composite insulator mechanics analysis}

\subsection{Operating conditions analysis}

Composite insulator stress is directly related to the state of the wires,the composite insulator produces stress concentration in the condition of the wires galloping and jumping off ice when there is wind. At the same time, the composite insulator suffers maximum load in this state. Running composite insulators as shown in figure 1, the mechanics problems of the short time of composite insulator rupture are happened at a certain moment load of fracture. This paper ignored two problems, one is to ignore the fatigue damage of the composite insulator in this period of time, the second is to ignore the change of the dynamic force of the composite insulator in the process of fracture. The biggest stress is directly selected to analysis the fracture.

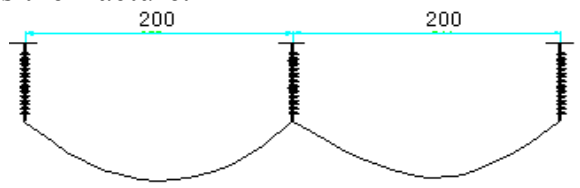

Figure 1. operation schematic diagram of insulators

At the overhead transmission lines in Yichang, the FXBW4-110/70 suspension insulator and LGJ-150/25 wire were used, which parameters are as follows.

Atmospheric conditions and load parameters; (1) Temperature of $-5^{\circ} \mathrm{C}$; (2)Wind speed of $25 \mathrm{~m} / \mathrm{s}$; (3) Icing thickness of $35 \mathrm{~cm}$; (4) Wire parameters;Diameter $17.1 \mathrm{~mm}$, Weight ratio carrier is $601 \mathrm{~kg} / \mathrm{km}$.Calculated the average span is $200 \mathrm{~m}$, the loads of compact transmission lines under extreme atmospheric conditions includes: Wire weight $F_{\text {wire }}=1202 \mathrm{~N}$;Icing wire weight $F_{\text {ice }}=8016.106 \mathrm{~N}$; When the load which from wind is perpendicular to the overhead wires, $F_{\text {wind }}=8185.225 \mathrm{~N}$. Taking into account the speed and direction of wind are uncertain,the load ranges form $1069.0165 \mathrm{~N}$ to $16201.3285 \mathrm{~N}$. 
Insulators parameters and load decomposition : Mandrel is a major part of composite insulators, which bears most of the mechanical load. The parameters are shown in Table 1。

Table1. The main parameters of mandrel in FXBW4110/70 composite insulators

\begin{tabular}{cccccccc}
\hline $\begin{array}{c}\text { Insulator } \\
\text { Model }\end{array}$ & $\begin{array}{c}\mathrm{Fa} / \\
\mathrm{kN}\end{array}$ & $\begin{array}{c}\mathrm{Fb} / \\
\mathrm{kN}\end{array}$ & $\mathrm{L} / \mathrm{mm} \mathrm{D} / \mathrm{mm} \mathrm{kg} \cdot \mathrm{m}-2$ & $\mathrm{GPa}$ & $\mathrm{u}$ \\
\hline $\begin{array}{c}\text { FXBW4- } \\
\text { 110/70 }\end{array}$ & 70 & 18 & 1200 & 30 & 1600 & 36.6 & 0.26 \\
\hline
\end{tabular}

Mandrel in the running process is mainly affected by three kinds of load, the load includes pulling stress, torsional stress and bending stress. Force diagram is shown in Figure 2.

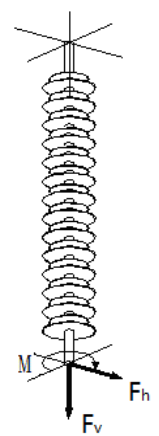

Figure2 The force diagram of composite insulator

\subsection{Tensile strain analysis}

Insulator mandrel, made of epoxy glass fiber, is a straight rod,It not only has a strong tensile properties, but also very light,So its weight can be ignored in counting. When subjected to axial tensile force, the axial deformation of Insulator mandrel is small, so transverse charges can be ignored.

For mandrel, the initial stage of the stress and strain are linear elastic. According to Hook's law [4], it can be got:

$$
\sigma=E \varepsilon
$$

In the above formula, $\varepsilon=\frac{\Delta L}{L}, \sigma=\frac{F_{N}}{A}=\frac{F_{V}}{A}, \mathrm{E}$ is the elastic modulus of the mandrel, $F_{V}$ is the vertical load on the mandrel, $\mathrm{A}$ is an end cross-sectional area.

The maximum $16.3 \mathrm{kN}$ is selected into force calculation. The tensile stress : $\sigma=23.1 \mathrm{Mpa}<<1000 \mathrm{Mpa}$. For the formula $F_{H}=F_{\max } / 3$, in which $F_{\max }=70 \mathrm{kN}$, is rated load of the composite insulator and 3 is taken as allowable safety coefficient. According to IEC standard,It is known the applied tensile load is not enough to make the composite insulator rupture immediately at the conditions of ice and wind load.

\subsection{Torsional strain analysis}

Because composite insulator is affected by the wave of conductor, the mandrel subjects to greater effect of the twisting moment M.Under the effect of this force, every circumferential line of the mandrel has an angle of rotation about the central axis.But the size,shape, and the distance between adjacent circular line remains the same.
For mandrel, the torsion angle of mandrel and the length of the mandrel have a great relationship.The relationship can be made by the torsion statics:

$$
M=G I_{p} \frac{d \varphi}{d x}
$$

In formula $I_{p}=I_{x}+I_{y}=\frac{\pi D^{4}}{32}, I_{p}$ is cross section facing the center of the polar moment of inertia of the moment (Cross-section secondary moment).Because $\frac{M}{G I_{p}} \quad$ is Constants, the formula(2) can be integrated:

$$
\varphi=\frac{M L}{G I_{p}}
$$

In which, $G=\frac{E}{2(1+\mu)}, M=F_{h} D$.

When the wind is horizontal, the load of the torsional is the biggest of all. Because of $F_{h}=8.2 \mathrm{KN}$, the applying moment $(\mathrm{M}=246 \mathrm{~N} \cdot \mathrm{m})$ and The torsion angle of mandrel ( $\phi=0.25 \approx 14.33$ ) can be figured out . the maximum shear stress is $46.4 \mathrm{Mpa}$, which is smaller than the mandrel shear value of $65 \mathrm{Mpa}[5]$.

\subsection{Bending strain analysis}

Under the situation of conductor galloping and jumping off ice,it will make the composite insulator over swing angle in the process of swinging. When taking waving into consideration,the movement of wire is irregular,so alone side the wire's horizontal tension can't be sure. According to Combined triangle,we can know that the maximum resultant in the horizontal direction is $16.3 \mathrm{kN}$.

Use the insulator which is applied to compact line to do the deflection test,It proves that insulators' link belongs to flexible link[6]. When under bigger bending load,it will be emerge large deformation.So, When we do the stress calculation of insulator, large deflection theory should be used.According to large deflection equation[78], As shown in the type(4):

$$
\frac{d^{2} \theta}{d S^{2}}+\frac{F}{E I} \cos \theta=0
$$

In the type: $\theta$ as the transverse corner; $S$ as the arc length; $I$ as the axis of inertia, $I=\frac{\pi D^{4}}{64}$.

Then ,use Galerkin method,it can obtain the solution of Large Deflection Equation in the free end:

$$
\frac{\widehat{w_{B}}}{L}=\sin \theta_{B}-\frac{2 \theta_{B}{ }^{2}}{3\left(\frac{F L^{2}}{E I}\right)^{\alpha}}
$$

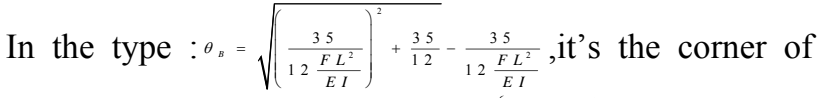
section $B$ in the ending of beam; $\alpha=\left\{\begin{array}{c}1, \text { 当 } \frac{F L^{2}}{E I} \leq 1 \\ 0.92, \quad \text { 当 } \frac{F L^{2}}{E I}>1\end{array}\right.$

So,we can get that $\frac{F^{2}}{E}=15.84>1, \theta_{B}=1.54 \mathrm{rad} \approx 88.3^{\circ}$, and the exact solutions of deflection in the free end $\widehat{w}_{B}=1.1016 \mathrm{~m}$.

According to the above analysis, under the limit tensile load or torsional load, unlikely to cause fracture of composite insulators immediately. Composite insulators under bending load acts, the load is $16.3 \mathrm{kN}$,close to the rated bending load $18 \mathrm{kN}$, It will not break immediately. 
So,It needs for further research about mandrel's bending deformation.Observing the bending force and stress concentration, find the risk of mandrel position that can be easily broken.Below that is about mandrel's ANSYS analysis when it under bending load.

\section{Simulation analysis of composite insulators}

\section{1 building models}

The ANSYS simulation model of Insulator mandrel is established, and its parameters are shown in table 1. This paper assumes that the top of the composite insulator is fixed on the tower,so the author gets rid of both ends hardware to research the conditions of bending directly,and looks mandrel as vertical cantilever beam structure

Among all mechanical study of the cantilever beam, BEAM188 ANSYS is the most widely used.BEAM188 is a three-dimensional beam element, which is based on Timoshenko beam theory end suitable for the analysis of linear and large rotation and the nonlinear analysis of large strain. The paper chooses BEAM188 unit.So the load is applied at the end directly, and the beam model is divided into 40 parts .It's shown in figure 3.

Boundary conditions:the movement of mandrel is limited in the plane, which only has three degrees of freedom (the $\mathrm{x}, \mathrm{y}$ and ROTZ) . One end that is fixed on the tower is Fixed constraint,and the other end bears horizontal force: $F=16.3 \mathrm{kN}$

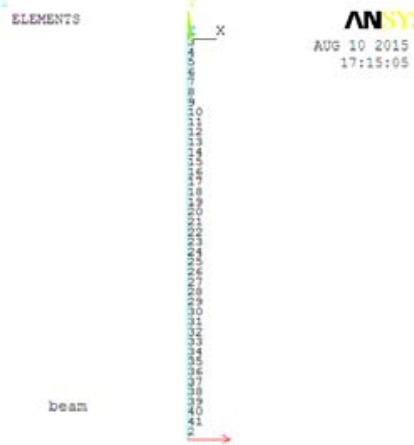

Figure 3 A model for the composite insulator mandrel

\subsection{Analysis of the Simulation results}

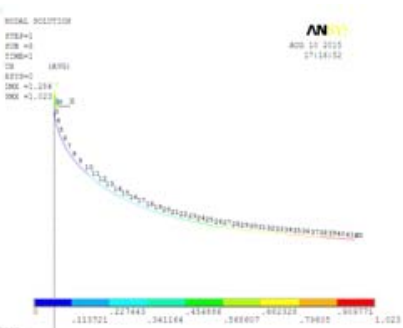

Figure 4. Displacement cloud picture of insulator

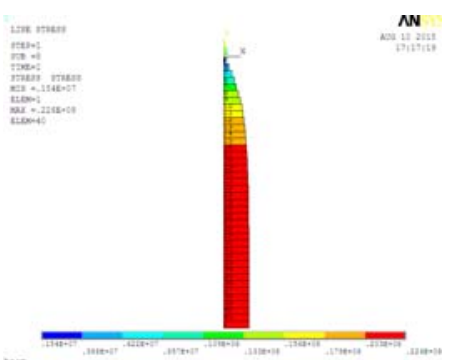

Figure 5. Axial stress cloud picture of the mandrel of insulator

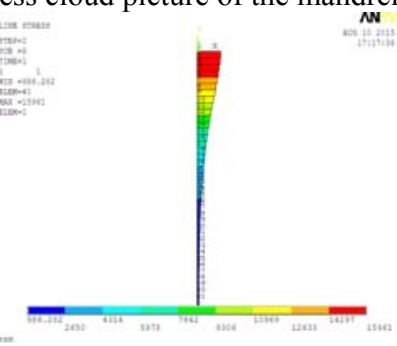

Figure 6. Moment cloud picture of the mandrel of insulator

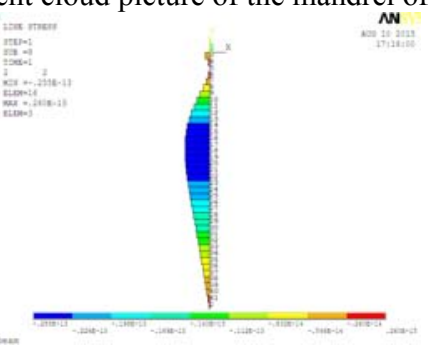

Figure 7. Shear cloud picture of the mandrel of insulator Figure 4 is an axial stress cloud picture of the mandrel of composite insulator, when the composite insulator was loaded $16.3 \mathrm{kN}$. According to the picture, the maximum horizontal displacement was $1.023 \mathrm{~m}$, it satisfies the large deflection theory,which proves that the composite insulator known as flexible link will deform obviously when given a relatively high load at horizontal direction.

Figure 5 is the moment cloud picture of the mandrel of composite insulator, we can see that maximum axial stress occurred at the end of the composite insulator which is near the conductor. When given a maximum load of $16.3 \mathrm{kN}$, the maximum axial stress was $22.6 \mathrm{MPa}$. Which is close to $23.1 \mathrm{MPa}$ which is calculated out when terminal face is vertical. Satisfying the large deflection theory perfectly, we calculated the terminal face angle is $88.3^{\circ}$. which further proves that the composite insulator known as flexible link will deform obviously when given a relatively high load at horizontal direction.

Figure 6 is the moment cloud picture of the mandrel of composite insulator, according to the picture, the maximum moment was $15961 \mathrm{~N} \cdot \mathrm{m}$ which occurred near the link of the tower and the fitting Shows that bending break usually occurred near the low voltage position of the tower, is exactly where the accident usually happened, which further explain the composite insulator is easy to bend and break quickly. Moment is only related to normal stress of the mandrel, the maximum normal stress is $602.4 \mathrm{Mpa}$, it is smaller than maximum broken stress of the composite insulator which is $855 \mathrm{MPa}$ [9].

Figure 7 is the shear cloud picture of the mandrel of composite insulator, according to the picture, the maximum shear force occurred at the unit 16 which is $0.246 \mathrm{E}-13 \mathrm{~N}$. According to the engineering practice, if the 
controlling factor of the mandrel of composite insulator meets the bending normal stress strength condition, it will basically satisfying the shear stress strength condition.

\section{Application and Prediction}

In the paper,the operation of the composite insulators broken into two cases.In one case,the extreme atmospheric conditions(ice thickness than $35 \mathrm{~cm}$ and the wind speed is greater than $25 \mathrm{~m} / \mathrm{s}$ )lead to bending fracture in short time. This case usually happened in short-term insulator(Figure8).In other case, brittle fracture occurs due to corrosion of the mandrel(Figure 9). Because the location of fracture is different in two cases, This paper presents that mandrel sheath breakage due to more factors in high-pressure position, such as acid, corrosion, and others. These factors led to the mechanical properties of the mandrel changed. In particular stress concentration position move down from the tower, eventually leading to brittle fracture occurred in high-pressure position near the end of the wire. The above studies are needed to confirm in further.

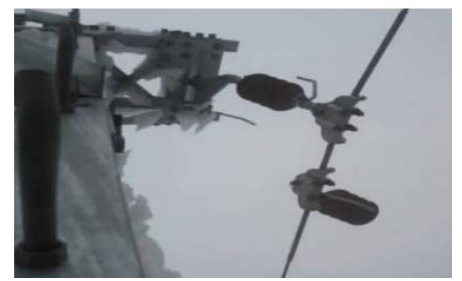

Figure 8 The breakage occurs in composite insulator which hanging three months in yunnan

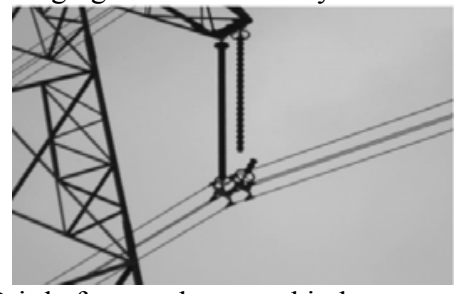

Figure9. Brittle fracture happened in long-term composite insulators

\section{Conclusions}

(1) Through calculation and analysis, FXBW4-110/70 composite insulator could withstand stress concentration caused by extreme weather conditions, in the Three Gorgee Area.In the short run time, the single action of tension,torsion and bending load couldn't make insulator fracture immediately.

(2) To eliminate the effects of tensile and torsional,the Simulation analysis of composite insulator shows that the fracture happen in the locations near towers more easily.

(3) Contrast mandrel axial stress diagram,bending moment diagram and shear diagram, it is concluded that,under the bending load, the strains of composite insulator mainly are affected by the bending normal stress, and shear stress has a minimal impact on it.

The above conclusions show that bending load has great influence on rupture of Suspension-Type composite insulator,It is need that increasing the flexural strength to avoid the accident of the break as far as possible

\section{Acknowledgement}

This work was financially supported by the Natural Science Foundation of China (Grant No.51475264) and the Pew Fund of Three Gorges University Master's Degree Thesis in 2015 (2015PY026).

\section{References}

[1] GUAN Zhi-cheng, PENG Gong-mao, WANG Liming, at al.Application and key technical study of composite insulators[J]. High Voltage Engineering, 2011, 37(3); 513-519

[2] YAN Wen-qiang, WANG Da-da, LI Wei-guo, at al.Joint diagnosis for a composite insulator fracture not because of the stress corrosion[J]. High Voltage Apparatus, 2013, 49(3); 103-109

[3] JIANG Xing-liang, SUN Cai-xin, GU Le-guan, at al.Power lines icing characteri cs of the Three Gorges district and a model of the accumulation of ice on electric on electric power lines[J]. Journal of Chongqing University(Natural Science Edition), 1998,21(2);16-19

[4] LIU Hong-wei.Mechanics of Materials( I )(4th Edition)[M].HIGHER EDUCATION PRESS, 2008

[5] WANG Xing-hua, WANG Zhong-li, ZHANG Genrong.Performance analysis of composite core rods[J]. FIBER COMPOSITES, 1997(2); 17-21+54

[6] WANG Ling*ming, SUN Bao-qiang, ZHANG Chuyan, at al.Mechanical analysis and calculation of phase-to-phase composite spacer on $750 \mathrm{kV}$ compact transmission lines $[\mathrm{J}]$. High Voltage Engineering, 2009, 35(10); 2551-2556

[7] HU Hui.Approximate solutionthe of large deflection of cantilever beam free end by concentrated force[J]. Journal of Shaoyang College, 1994(3), 213-214

[8] ZHAO Ze-ang, DENG Zong-bai, SONG An-ping.An approximation method for the large deflection of cantilever beams[J]. Mechanics in Engineering, , 2014, 36(3); 341-344+346

[9] BO Xue-wei, WANG Li-ming, SUN Bao-qiang, at al.Study on Electrical and Mechanical Properties of Phase-to-phase Composite Spacer on $500 \mathrm{kV}$ Compact Line[J]. High Voltage Apparatus, 2011, $47(2) ; 43-47+52$ 